\title{
Ensuring the Safety of Yellow Fever Vaccination in Travelers-The Experience at a Large U.S. Academic Medical Center in Colorado
}

\author{
Mehdi Bandali ${ }^{1}{ }^{(0}$, Jonathan Schultz ${ }^{2}{ }^{\circledR}$, Kimlien Than ${ }^{3}$, Donna McGregor ${ }^{2}$, Solana Archuleta ${ }^{1}$,

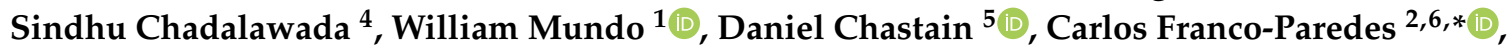 \\ Elaine Reno ${ }^{6}$ and Andrés F. Henao-Martínez ${ }^{2}$ D \\ 1 School of Medicine, University of Colorado Anschutz Medical Campus, Aurora, CO 80045, USA; \\ mohamed.bandali@cuanschutz.edu (M.B.); solana.archuleta@cuanschutz.edu (S.A.); \\ william.mundo@cuanschutz.edu (W.M.) \\ 2 Division of Infectious Diseases, Department of Medicine, University of Colorado Anschutz Medical Campus, \\ Aurora, CO 80045, USA; jonathan.schultz@cuanschutz.edu (J.S.); donna.mcgregor@cuanschutz.edu (D.M.); \\ andres.henaomartinez@cuanschutz.edu (A.F.H.-M.) \\ 3 School of Pharmacy, University of Colorado Anschutz Medical Campus, Aurora, CO 80045, USA; \\ kimlien.than@cuanschutz.edu \\ $4 \quad$ NRI General Hospital, Pradesh 522503, India; chsindhu@gmail.com \\ 5 Department of Clinical and Administrative Pharmacy, University of Georgia College of Pharmacy, Albany, \\ GA 30901, USA; daniel.chastain@uga.edu \\ 6 Department of Emergency Medicine, Hospital Infantil de México, Federico Gómez, México City 06720, \\ Mexico; elaine.reno@cuanschutz.edu \\ * Correspondence: carlos.franco-paredes@cuanschutz.edu; Tel.: +1-(720)-848-0820; Fax: +1-(720)-848-0191
}

Received: 19 June 2020; Accepted: 25 July 2020; Published: 29 July 2020

\begin{abstract}
Background: Yellow fever (YF) virus has the potential to cause fatal outcomes among at-risk individuals visiting endemic areas. Vaccinating travelers who are at risk is necessary to prevent virus-related life-threatening complications. We lack data on the clinical features of persons seeking YF vaccination. We aim to describe the characteristics of a cohort of persons receiving the YF vaccine before travel. Methods: A retrospective analysis of 964 travelers receiving the YF vaccine (Stamaril ${ }^{\circledR}$ ) from Oct 2016 to Jul 2019 was performed at the University of Colorado Hospital, U.S. Percentages, means, and standard deviations were calculated. A multivariate logistic regression model was built to evaluate the association between receiving YF vaccination less than 10 days before departure and visiting friends and relatives (VFR). Results: The average age of the subjects was $39 \pm 18$ years with a range of nine months to 83 years. Persons who were 60 years of age and older represented $17 \%$. Women consisted of $52 \%$, and most of the travelers were Caucasians (64\%). Travelers reported traveling to Africa (57\%) or South America (40\%). The primary destinations for travelers overall were Kenya (19\%), Uganda (11\%), and Tanzania (11\%) in Africa; and Peru (14\%) and Brazil $(13 \%)$ in South America. The most common reasons for travel included leisure (44\%), VFR (18\%), and mission trips (10\%). Comorbidities included a history of hematologic disorders (4\%), HIV infection $(2 \%)$, and diabetes mellitus ( $3 \%)$. The average duration between vaccine administration and travel was 43 days. Those VFR were two times more likely to receive the YF vaccination $<10$ days before departure. Conclusions: Identifying the type of travel, itinerary, and underlying medical conditions allows providers to administer the YF vaccine to travelers safely. There is a need to identify strategies to improve the timing of YF vaccination among VFR travelers.
\end{abstract}

Keywords: yellow fever virus; yellow fever vaccine; travel medicine; health policy 


\section{Introduction}

Yellow fever (YF) is a hemorrhagic disease caused by a flavivirus and transmitted by the Aedes aegypti mosquito, which is found in parts of tropical South America and sub-Saharan Africa. Since the early 1990s, the World Health Organization (WHO) estimates that there have been 200,000 cases of YF and 30,000 deaths due to the disease worldwide [1]. An analysis of African data sources in 2013 estimated that the burden of YF was 130,000 severe cases and 78,000 deaths [2].

Treatment for patients with YF is mainly supportive, as there is no specific antiviral therapy available. However, the YF vaccine is widely used for the prevention of YF in travelers, and for people living in endemic areas. There are 20-60 million doses of the vaccine distributed annually [3]. YF-VAX ${ }^{\circledR}$ and Stamaril ${ }^{\circledR}$ are live attenuated vaccines prepared by culturing the 17D-204 strain of the virus in chicken embryos, and their efficacy is based upon the development of neutralizing antibodies [4]. The vaccine has been used since the 1930s when it was first developed. WHO modified the length of validation by the vaccine in 2016 from 10 years to lifelong duration for most individuals [5]. In the U.S., the YF vaccine is primarily given as prophylaxis to military personnel and patients at risk due to travel to endemic areas. Sanofi held the manufacturing of YF-VAX ${ }^{\circledR}$ in 2016 due to factory production issues, and the company made available an alternative vaccine, Stamaril ${ }^{\circledR}$, which is administered in the U.S. through an FDA-approved expanded access program. Standard clinical practice of screening patients during the pre-travel encounter is essential to prevent complications associated with YF vaccination. YF is a live attenuated vaccine with known serious adverse events, including vaccine-associated viscerotropic disease (YEL-AVD) and neurotropic disease (YEL-AND). Risk factors include uncontrolled HIV infection, 60 years and older patients [6], and other immunocompromised conditions. The subgroup of patients traveling to visit friends and relatives (VFR) can be a particularly vulnerable population at higher risk for some preventable infections, such as malaria, due to loss of previous immunity, and a lesser likelihood to seek pre-travel advice or take prophylaxis, while going back to their home countries [7,8]. There are limited studies in the U.S. that describe the patient population receiving the YF vaccine. This study aimed to identify important descriptors of patients getting the YF vaccine before travel, including patients traveling to visit friends and relatives. This information can aid public health agencies to enhance strategies to increase immunizations of patients at risk and avoid complications.

\section{Methods}

\subsection{Ethics Statement}

The present investigation complies with the Health Insurance Portability and Accountability Act (HIPAA) according to the Colorado Multiple Institutional Review Board (COMIRB) at the University of Colorado Denver. Patients received the YF vaccine through an approved Sanofi Pasteur Inc. Protocol Number STA00011, Expanded Access IND Program to Provide Stamaril ${ }^{\circledR}$ YF Vaccine (17D-204 strain) to Persons in the United States (Quorum Review File \#32032). Analysis of clinical data has been performed under an approved protocol (COMIRB Protocol 17-1032).

\subsection{Patients and Data Collection}

Data from patients receiving the Stamaril ${ }^{\circledR}$ vaccine at the University of Colorado Hospital clinic from 31 October 2016 to 7 July 2019, were submitted for data extraction. Electronic medical records (EPIC) were automatically interrogated for the cohort of travelers through a software supported by Health Data Compass Data Warehouse project (healthdatacompass.org). Study data were collected and managed using REDCap electronic data capture tools hosted at the University of Colorado Denver. The following variables were automatically collected: gender, age, race, state of residency, date of YF vaccine, and the following comorbidities based on International Classification of Diseases (ICD) codes: diabetes mellitus, neoplasms, HIV infection, history of hematology-immune disorders, and pregnancy (see Appendix A for full ICD-9, and ICD-10 code definitions). VFR was defined as a form of travel 
wherein the purpose of the trip or the type of accommodation was visiting friends and/or relatives as consigned in the patient's history. The following variables were manually collected through chart review: verification of vaccine date if it was unavailable per the automatic search, pregnancy at the time of vaccine administration, the reason for travel, the continent of travel, and destination countries. Some travelers had missing information on key variables (Table 1).

Table 1. A cohort of travelers receiving the yellow fever vaccine at the University of Colorado Hospital.

\begin{tabular}{|c|c|c|c|c|}
\hline Variables & $\begin{array}{c}\text { Total } \\
(\mathrm{n}=964)\end{array}$ & $\begin{array}{c}\text { Visit F\&R, N = } 170 \\
(18 \%)\end{array}$ & $\begin{array}{l}\text { Other Reason, } \\
\mathrm{N}=794(82 \%)\end{array}$ & $p$-Value \\
\hline Age (years), mean (SD) & $39(18)$ & $30(20)$ & $41(17)$ & $<0.0001$ \\
\hline Age $\geq 60$ years old & $167(17 \%)$ & $18(11 \%)$ & $149(19 \%)$ & 0.01 \\
\hline Sex, female & $502(52 \%)$ & $74(44 \%)$ & $428(54 \%)$ & 0.01 \\
\hline Race & & & & $<0.0001$ \\
\hline White & $614(64 \%)$ & $36(21 \%)$ & $578(73 \%)$ & \\
\hline African American & $142(15 \%)$ & $104(61 \%)$ & $38(5 \%)$ & \\
\hline Other & $208(22 \%)$ & $30(18 \%)$ & $178(22 \%)$ & \\
\hline Out of Colorado State & $41(4 \%)$ & $5(3 \%)$ & $36(5 \%)$ & 0.35 \\
\hline Pregnancy & $11(2 \%)$ & $5(6 \%)$ & $6(1 \%)$ & 0.004 \\
\hline Hematologic/Immunulogic Disease & $36(4 \%)$ & $9(5 \%)$ & $27(3 \%)$ & 0.237 \\
\hline Diabetes Mellitus & $27(3 \%)$ & $6(4 \%)$ & $21(3 \%)$ & 0.526 \\
\hline Neoplasm & $72(7 \%)$ & $7(4 \%)$ & $65(8 \%)$ & 0.07 \\
\hline HIV & $22(2 \%)$ & $12(7 \%)$ & $10(1 \%)$ & $<0.0001$ \\
\hline \multicolumn{5}{|l|}{ Destination } \\
\hline Africa & $551(57 \%)$ & $146(86 \%)$ & $405(51 \%)$ & $<0.0001$ \\
\hline South America & $387(40 \%)$ & $22(13 \%)$ & $365(46 \%)$ & \\
\hline Other & $26(3 \%)$ & $2(1 \%)$ & $24(3 \%)$ & \\
\hline $\begin{array}{l}\text { Time between vaccine administration } \\
\text { and depature (days), mean (SD) }\end{array}$ & $41(38)$ & $34(39)$ & $43(38)$ & 0.0049 \\
\hline Vaccination $<10$ days & $110(11 \%)$ & $30(18 \%)$ & $80(10 \%)$ & 0.005 \\
\hline
\end{tabular}

\subsection{Statistical Analysis}

The means and standard deviations for continuous variables were calculated. For categorical variables, frequencies and percentages were calculated. Patient characteristics were compared between those reporting to visit friends and relatives versus other reasons of travel using chi-squared, students $t$-tests, or Fisher exact tests. A multivariate logistic regression model was built to evaluate the association between those receiving YF vaccination less than 10 days before departure and those VFR, after controlling for confounders of age, sex, race, and the continent of travel. All analyses were conducted in SAS 9.4. We selected the 10 days based on WHO recommendation of the optimal time of immunization against YF before traveling to endemic areas [9].

Data access: The corresponding author had full access to all the data in the study and had final responsibility for the decision to submit the manuscript for publication. The datasets generated during and/or analyzed during the current study are available from the corresponding author upon reasonable request.

\section{Results}

\subsection{Clinical Characteristics of Patients Receiving the Yellow Fever Vaccine:}

Of 964 subjects, the average age of travelers receiving the vaccine was 39 years with a range from nine months to 83 years (Table 1$)$. There were more females (52\%), and most of the travelers were identified as Caucasian (64\%). Most travelers were from the State of Colorado (96\%). Travelers predominantly reported travel to Africa $(57 \%)$ or South America $(40 \%)$, among which the primary destinations included Kenya (19\%), Uganda (11\%), and Tanzania (11\%) in Africa; and Peru (14\%) and Brazil (13\%) in South America (Figure 1). The most common reasons for travel included leisure $(44 \%)$, followed by VFR (18\%) and mission trips (10\%) (Figure 2). Comorbidities were uncommon but included a history of neoplasm (7\%), hematologic/immunologic disorders (4\%), HIV infection 
$(2 \%)$, and diabetes mellitus (3\%). Heme/immune diagnosis captured through ICD codes included benign heme disorders such as polycythemia, pancytopenia, sickle cell trait, thalassemia, history of deep venous thrombosis, previous use of systemic lupus erythematous medications, and unspecified immune disorders (Appendix A). Common ICD neoplasm diagnoses captured were benign tumors of the skin, prostate, and uterus; and history of colorectal cancer, melanoma, multiple myeloma, uterus carcinoma, kidney cancer, bladder cancer, and others (Appendix A). The average duration between vaccine administration and travel was 43 days. No evidence of mild or life-threatening reactions to Stamaril ${ }^{\circledR}$ occurred in this large cohort.

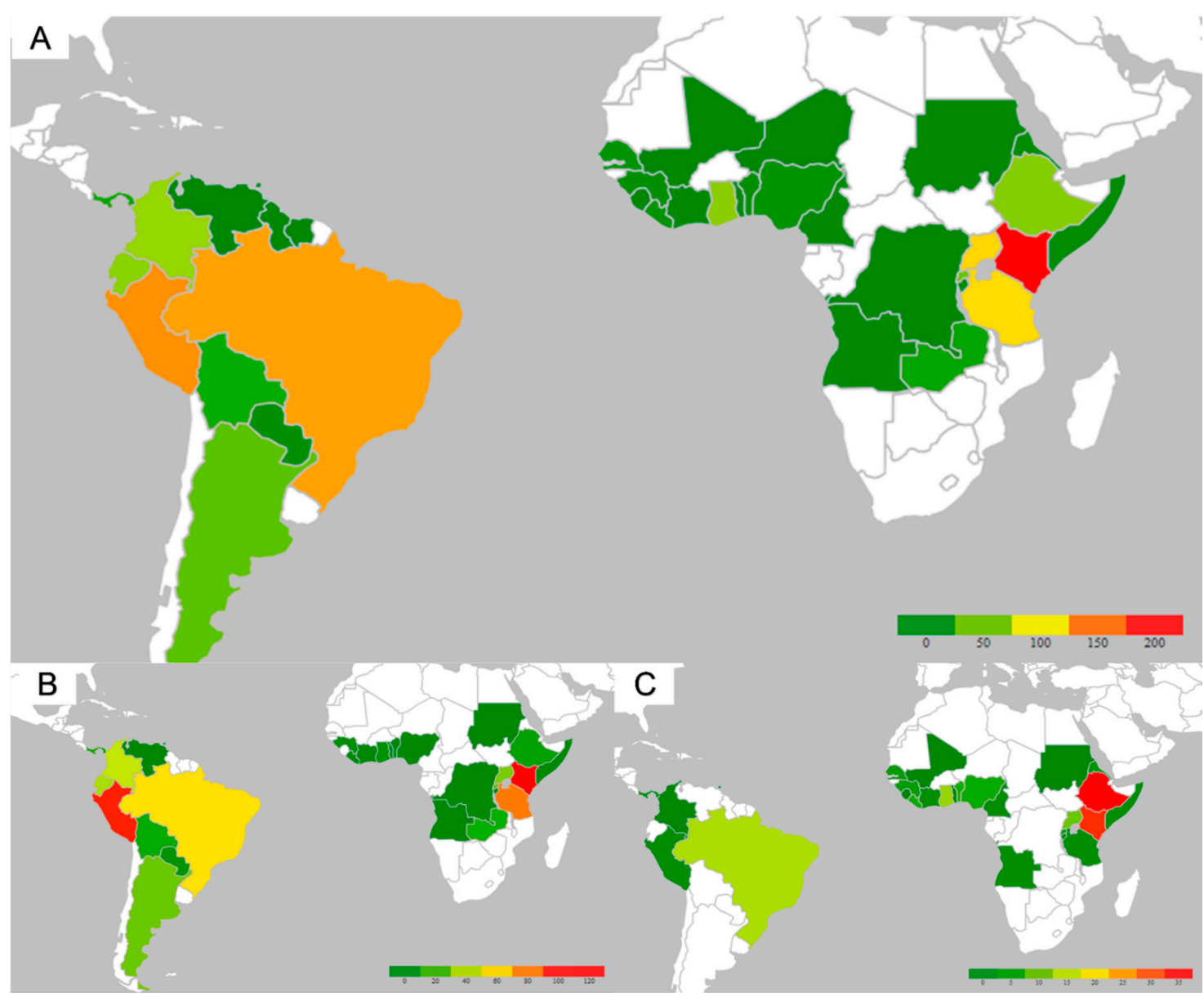

Figure 1. Heat map of destinations among patients receiving the yellow fever (YF) vaccine. (A). Heat map of countries of destination for the total cohort. (B). Heat map for travelers going for leisure. (C). Heat map for travelers going to visit friends and family. The density of patients is represented by color bars. 


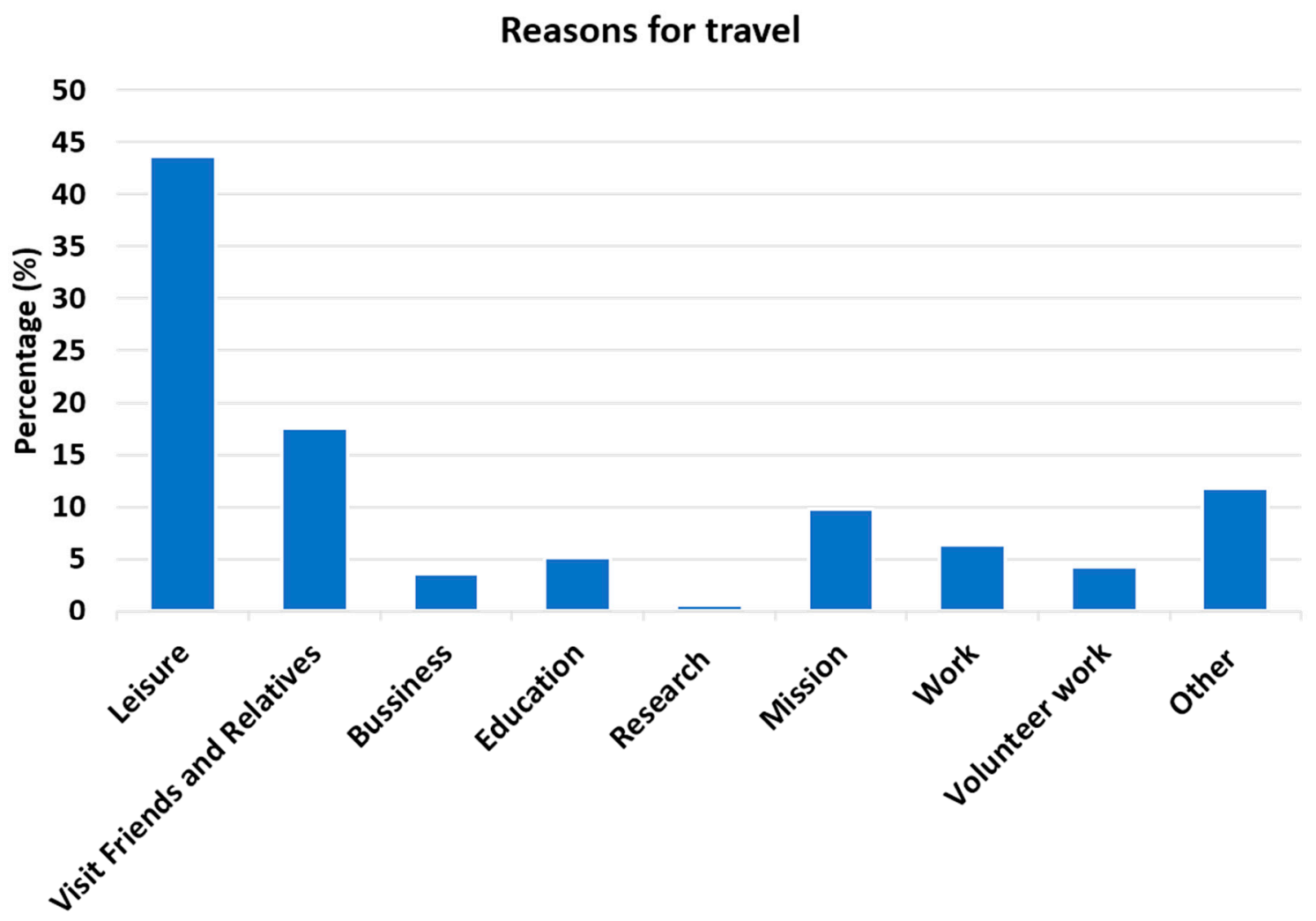

Figure 2. Reasons for travel among patients receiving the YF vaccine $(n=964)$.

Travelers who were 60 years of age and older represented $17 \%$ of the total study population. They were $53 \%$ women, predominantly white $(79 \%)$, and mostly traveling for leisure $(63 \%)$. They visited Africa (52\%) and South America (47\%) more often and had plenty of time to receive the vaccine before departure with a mean of 50 days. Kenya (23\%), Tanzania (22\%), Brazil (24\%), and Peru (16\%) were popular destinations among these travelers. Only $7 \%$ received the vaccine less than 10 days from departure. Sixty years or older travelers had higher rates history of heme-immune conditions $(8 \%)$, diabetes mellitus ( $8 \%)$, and neoplasms (22\%).

Since the vaccine is licensed only to infants older than nine months of age, we only had four infants less than one year of age in our cohort, representing $0.4 \%$. We did not have any reported side effects or complications in this group of travelers.

\subsection{Travelers Visiting Friends and Relatives}

Travelers visiting their friends and relatives were more predominantly men (56\%), younger, and identified as African Americans for their primary ethnicity. Women in this subgroup were more likely to be pregnant and more likely to be HIV positive, but less likely to have a history of cancer. They were more likely to visit Africa as opposed to South America, and they had less time between vaccine administration and travel departure. Common destinations were Kenya, Ethiopia, and less commonly Brazil (Figure 1C). VFR travelers were more likely to receive the vaccine less than 10 days before departure compared to other reasons for travel $(18 \%$ vs. $10 \%, p=0.005)$. Those VFR were 2.2 times (OR 2.2 (1.3-3.7), $p=0.003$ ) more likely to receive the YF vaccination $<10$ days before departure, after controlling for confounders of age, sex, race, and destination of Africa vs. South America.

\section{Discussion}

We describe the clinical characteristics of a cohort of travelers seeking YF vaccination at a U.S medical center. Some of those travelers presented themselves as family groups. Most were young adults, but the age varied widely from infants to seniors. In Colorado, most travelers were Caucasian, 
had a few comorbidities, and traveled to Africa most often. Travelers sought YF vaccination on an average of about a month and a half before their departure date. The subgroup of VFR travelers was younger, of African American descent, traveling to the African continent, more often pregnant, and had a higher likelihood of having an HIV infection.

We also showed that VFR travelers were more likely to receive the YF vaccine at a suboptimal time before travel. WHO recommends immunization against $\mathrm{YF}$ at least 10 days before travel to endemic areas [9]. Studies in travel clinics have shown inadequate timing of the YF vaccine before travel in children [10]. Those VFR may have a harder time making travel clinic appointments and may present just before travel and may be less prepared to take appropriate preventative measures [11].

Receiving the vaccine less than 10 days prior can also have implications for possible denial of entry or increased paperwork at the country of destination. Those VFR may also not recognize the specific country requirement of YF vaccination until just shortly before departure. VFR travelers carry a higher risk of acquired travel-related illnesses such as Hepatitis A, typhoid, malaria, soil-transmitted helminths, and influenza [12]. Specific risk factors associated with the increased threat of illness among VFR include longer stays, decreased pre-travel health plans, sick contacts while abroad, and poorer sanitary conditions during their stay. Public health interventions can aim to increase rates and enhance the optimal timing of YF vaccination among those VFR.

We have shown a large cohort of travelers who safely received the YF vaccine before travel. Since the rate of adverse events with the Yellow vaccine is of about three events per 100,000 doses [13], with our relatively small representative sample we cannot extrapolate a different safety profile. Nevertheless, through standardized travel advice encounters, we safely delivered the vaccine to more than 150 travelers aged 60 years or older, travelers with controlled HIV, and history of cancer, pregnancy, or heme-immune disorders not listed as absolute contraindications. Although travel clinic providers screened travelers for contraindications to receive the YF vaccine, the more comprehensive interrogation of our electronic medical records found a small rate of non-prohibitive relative contraindications in some travelers. We still encourage the avoidance of vaccination in travelers with relative contraindications if the risk of YF acquisition during travel is deemed low, but our findings suggest vaccination is safe in this relatively small cohort among travelers older than 60 years of age. Our cohort delivered some safety evidence of YF vaccine administration among travelers with those listed conditions. This data can reassure clinicians and travelers with a history of those conditions to make pre-travel decisions where the $Y F$ vaccine administration is mandatory.

Previous reports in Nigeria have documented the safe administration of the YF vaccine during pregnancy [14]. Administration of the vaccine to HIV-infected individuals with CD4 counts greater than 500 cells $/ \mathrm{mm}^{3}$ is safe [15]. YF vaccine has been also administered safely in immunocompromised patients after the withdrawal of their immunosuppressive therapy $[16,17]$.

Our population of travelers visiting family and friends reflects the diversity of African immigrants in Aurora, Colorado. A significant number of travelers seeking pre-travel advice will benefit from a continued comprehensive pre-travel screening of immunocompromised conditions.

Providing the YF vaccine remains a critical public health strategy to decrease transmission and disease. Although overall coverage for the YF vaccine has increased in endemic countries [18], travelers are an important target for this preventive strategy as well. Data from the recent Brazilian outbreak found a case fatality of up to $40 \%$ among unimmunized travelers [19].

Models incorporating clinical features have been important to showcase disease burden and to enhance vaccination strategies [20]. The study of high-risk populations can inform the best vaccine policies [21]. VFR travelers are considered a high-risk population. We recommend public health policies to enhance the inclusion of vulnerable populations such as people VFR for YF prophylaxis. We should explore policies such as outreach community messages on the importance of pre-travel health care among foreign-born populations in the US. Additional considerations include community health workers reaching VFR communities to explain the importance of pre-travel vaccination and assessing individual risks. 
There are a few limitations to this study. The retrospective selection of data limits the reliability and number of variables analyzed. Misdiagnosis or irrelevant past medical history could have been selected through the automatic ICD screening of the previous diagnosis. However, selection bias was decreased through the automatic collection of some key risk factor variables. Missing data occurred in some medical records as well. We did not have data on foreign-born status among the VFR travelers, which can also account for different clinical characteristics or outcomes.

YF vaccine remains a priority for decreasing disease burden. Coloradans seeking the vaccine represent the current demographics of our community. Despite the history of uncommon well-known comorbidities, YF vaccination was effective and safe. YF disease remains a potentially lethal complication during travel. The current outbreak in Nigeria and the 2018 outbreak in Brazil, both with high case fatality ratios, highlight that prevention strategies are a priority. Efforts should be enhanced to continue YF disease prevention strategies in travel clinics throughout the United States.

Author Contributions: M.B. performed data collection and helped in drafting the first version of the manuscript. J.S. provided critical edits to the manuscript and assisted with the statistical analysis. K.T., D.M., and E.R. assisted with data collection and provided edits to the manuscript. S.A., S.C., W.M., D.C., and C.F.-P. provided critical edits to the manuscript. A.F.H.-M. had the original research idea, assisted with data collection, helped to draft the manuscript, and assisted with data analysis. All authors have read and agreed to the published version of the manuscript.

Funding: This research received no external funding.

Acknowledgments: No funding agencies had any role in the preparation, review, or approval of this manuscript. This publication was supported by NIH/NCRR Colorado CTSI grant Number UL1 RR025780. Its contents are the authors' sole responsibility and do not necessarily represent official NIH views.

Conflicts of Interest: A.H.M. was the recipient of a K12-clinical trial award as a co-principal investigator for the Expanded Access IND Program (EAP) to provide Stamaril Vaccine to Persons in the United States for Vaccination against Yellow Fever. The rest of the authors declare no conflict of interest.

\section{Appendix A}

Table A1. List of diagnoses by ICD codes in yellow fever recipients, University of Colorado Hospital, Denver, 2016-2019.

\begin{tabular}{|c|c|c|c|}
\hline ICD & ICD-Code & Diagnosis & Categories \\
\hline ICD-9-CM & 250.8 & Xanthoma diabeticorum & $\mathrm{DM}$ \\
\hline ICD-9-CM & 250.6 & $\begin{array}{l}\text { Well controlled type } 2 \text { diabetes mellitus with peripheral neuropathy } \\
\text { (HC code) }\end{array}$ & $\mathrm{DM}$ \\
\hline ICD-9-CM & 250.7 & $\begin{array}{c}\text { Well controlled type } 2 \text { diabetes mellitus with peripheral circulatory } \\
\text { disorder (HC code) }\end{array}$ & $\mathrm{DM}$ \\
\hline ICD-9-CM & 250 & Well controlled type 2 diabetes mellitus (HC code) & $\mathrm{DM}$ \\
\hline ICD-9-CM & 250.61 & $\begin{array}{l}\text { Well controlled type } 1 \text { diabetes mellitus with peripheral neuropathy } \\
\text { (HC code) }\end{array}$ & $\mathrm{DM}$ \\
\hline ICD-9-CM & 250.01 & Well controlled type 1 diabetes mellitus (HC code) & $\mathrm{DM}$ \\
\hline ICD-9-CM & 250.5 & Visual loss due to diabetes mellitus (HC code) & DM \\
\hline ICD-9-CM & 250.9 & Unspecified diabetes mellitus with unspecified complications & DM \\
\hline ICD-9-CM & 250.02 & Uncontrolled type II diabetes mellitus with nephropathy & $\mathrm{DM}$ \\
\hline ICD-9-CM & 250.92 & Uncontrolled type 2 diabetes mellitus with complication (HC code) & $\mathrm{DM}$ \\
\hline ICD-9-CM & 249.6 & Ulnar neuropathy due to secondary DM (HC code) & DM \\
\hline ICD-9-CM & 250.81 & Type I diabetes with complications & DM \\
\hline ICD-10-CM & E11.9 & Type 2 diabetes mellitus without complications & $\mathrm{DM}$ \\
\hline
\end{tabular}


Table A1. Cont.

\begin{tabular}{|c|c|c|c|}
\hline ICD & ICD-Code & Diagnosis & Categories \\
\hline ICD-10-CM & E11.311 & $\begin{array}{l}\text { Type } 2 \text { diabetes mellitus with unspecified diabetic retinopathy with } \\
\text { macular edema }\end{array}$ & $\mathrm{DM}$ \\
\hline ICD-10-CM & E11.8 & Type 2 diabetes mellitus with unspecified complications & $\mathrm{DM}$ \\
\hline ICD-10-CM & E11.69 & Type 2 diabetes mellitus with other specified complication & $\mathrm{DM}$ \\
\hline ICD-10-CM & E11.39 & Type 2 diabetes mellitus with other diabetic ophthalmic complication & $\mathrm{DM}$ \\
\hline ICD-10-CM & E11.49 & Type 2 diabetes mellitus with other diabetic neurological complication & $\mathrm{DM}$ \\
\hline ICD-10-CM & E11.59 & Type 2 diabetes mellitus with oth circulatory complications & $\mathrm{DM}$ \\
\hline ICD-10-CM & E11.3393 & $\begin{array}{c}\text { Type } 2 \text { diabetes mellitus with moderate nonproliferative diabetic } \\
\text { retinopathy without macular edema, bilateral }\end{array}$ & $\mathrm{DM}$ \\
\hline ICD-10-CM & E11.3293 & $\begin{array}{l}\text { Type } 2 \text { diabetes mellitus with mild nonproliferative diabetic } \\
\text { retinopathy without macular edema, bilateral }\end{array}$ & $\mathrm{DM}$ \\
\hline ICD-10-CM & E11.3219 & $\begin{array}{l}\text { Type } 2 \text { diabetes mellitus with mild nonproliferative diabetic } \\
\text { retinopathy with macular edema, unspecified eye }\end{array}$ & $\mathrm{DM}$ \\
\hline ICD-10-CM & E11.3213 & $\begin{array}{l}\text { Type } 2 \text { diabetes mellitus with mild nonproliferative diabetic } \\
\text { retinopathy with macular edema, bilateral }\end{array}$ & $\mathrm{DM}$ \\
\hline ICD-10-CM & E11.649 & Type 2 diabetes mellitus with hypoglycemia without coma & DM \\
\hline ICD-10-CM & E11.65 & Type 2 diabetes mellitus with hyperglycemia & $\mathrm{DM}$ \\
\hline ICD-10-CM & E11.621 & Type 2 diabetes mellitus with foot ulcer & $\mathrm{DM}$ \\
\hline ICD-10-CM & E11.42 & Type 2 diabetes mellitus with diabetic polyneuropathy & DM \\
\hline ICD-10-CM & E11.40 & Type 2 diabetes mellitus with diabetic neuropathy, unsp & $\mathrm{DM}$ \\
\hline ICD-10-CM & E11.610 & Type 2 diabetes mellitus with diabetic neuropathic arthropathy & $\mathrm{DM}$ \\
\hline ICD-10-CM & E11.43 & Type 2 diabetes mellitus with diabetic autonomic (poly)neuropathy & $\mathrm{DM}$ \\
\hline ICD-10-CM & E11.44 & Type 2 diabetes mellitus with diabetic amyotrophy & $\mathrm{DM}$ \\
\hline ICD-10-CM & E11.3299 & Type 2 diab with mild nonp rtnop without macular edema, unsp & DM \\
\hline ICD-10-CM & E10.9 & Type 1 diabetes mellitus without complications & $\mathrm{DM}$ \\
\hline ICD-10-CM & E10.649 & Type 1 diabetes mellitus with hypoglycemia without coma & $\mathrm{DM}$ \\
\hline ICD-10-CM & E10.65 & Type 1 diabetes mellitus with hyperglycemia & $\mathrm{DM}$ \\
\hline ICD-10-CM & E13.44 & Other specified diabetes mellitus with diabetic amyotrophy & $\mathrm{DM}$ \\
\hline ICD-9-CM & 359.1 & Wielander's distal dystrophy (HC code) & Heme/Immune \\
\hline ICD-9-CM & 287.2 & Vasculitis, hemorrhagic & Heme/Immune \\
\hline ICD-9-CM & 287.5 & Unspecified thrombocytopenia & Heme/Immune \\
\hline ICD-9-CM & 279.3 & Unspecified immunity deficiency & Heme/Immune \\
\hline ICD-9-CM & 287.9 & Unspecified hemorrhagic conditions & Heme/Immune \\
\hline ICD-9-CM & 279.9 & Unspecified disorder of immune mechanism & Heme/Immune \\
\hline ICD-9-CM & 795.09 & Unexplained endometrial cells on cervical Pap smear & Heme/Immune \\
\hline ICD-9-CM & 795.51 & Tuberculin test reaction & Heme/Immune \\
\hline ICD-10-CM & D69.6 & Thrombocytopenia, unspecified & Heme/Immune \\
\hline ICD-10-CM & D56.3 & Thalassemia minor & Heme/Immune \\
\hline ICD-9-CM & 795.79 & Systemic lupus erythematosus inhibitor (HC code) & Heme/Immune \\
\hline ICD-9-CM & 203 & Stage III multiple myeloma (HC code) & Neoplasms \\
\hline ICD-10-CM & D57.3 & Sickle-cell trait & Heme/Immune \\
\hline ICD-10-CM & D75.1 & Secondary polycythemia & Heme/Immune \\
\hline ICD-10-CM & D86.3 & Sarcoidosis of skin & Heme/Immune \\
\hline ICD-9-CM & 795.52 & $\begin{array}{l}\text { Response to cell-mediated gamma interferon antigen without active } \\
\text { tuberculosis }\end{array}$ & Heme/Immune \\
\hline
\end{tabular}


Table A1. Cont.

\begin{tabular}{|c|c|c|c|}
\hline ICD & ICD-Code & Diagnosis & Categories \\
\hline ICD-10-CM & D69.1 & Qualitative platelet defects & Heme/Immune \\
\hline ICD-10-CM & D68.52 & Prothrombin gene mutation & Heme/Immune \\
\hline ICD-9-CM & 279.49 & Progesterone dermatitis & Heme/Immune \\
\hline ICD-9-CM & 795.05 & Positive cervical papilloma DNA test & Neoplasms \\
\hline ICD-10-CM & Z86.73 & $\begin{array}{l}\text { Personal history of transient ischemic attack (TIA), and cerebral } \\
\text { infarction without residual deficits }\end{array}$ & Heme/Immune \\
\hline ICD-10-CM & Z86.711 & Personal history of pulmonary embolism & Heme/Immune \\
\hline ICD-10-CM & Z86.718 & Personal history of other venous thrombosis and embolism & Heme/Immune \\
\hline ICD-10-CM & Z86.59 & Personal history of other mental and behavioral disorders & Heme/Immune \\
\hline ICD-10-CM & Z92.89 & Personal history of other medical treatment & Heme/Immune \\
\hline ICD-10-CM & Z86.19 & Personal history of other infectious and parasitic diseases & Heme/Immune \\
\hline ICD-10-CM & Z86.69 & $\begin{array}{l}\text { Personal history of other diseases of the nervous system and sense } \\
\text { organs }\end{array}$ & Heme/Immune \\
\hline ICD-10-CM & Z86.79 & Personal history of other diseases of the circulatory system & Heme/Immune \\
\hline ICD-10-CM & Z86.018 & Personal history of other benign neoplasm & Neoplasms \\
\hline ICD-10-CM & Z86.13 & Personal history of malaria & Heme/Immune \\
\hline ICD-10-CM & Z86.008 & Personal history of in-situ neoplasm of other site & Heme/Immune \\
\hline ICD-10-CM & Z86.39 & Personal history of endo, nutritional and metabolic disease & Heme/Immune \\
\hline ICD-10-CM & Z86.2 & $\begin{array}{l}\text { Personal history of diseases of the blood and blood-forming organs and } \\
\text { certain disorders involving the immune mechanism }\end{array}$ & Heme/Immune \\
\hline ICD-10-CM & Z86.010 & Personal history of colonic polyps & Heme/Immune \\
\hline ICD-10-CM & Z92.21 & Personal history of antineoplastic chemotherapy & Heme/Immune \\
\hline ICD-9-CM & 795.03 & $\begin{array}{l}\text { Papanicolaou smear of cervix with low grade squamous intraepithelial } \\
\text { lesion (LGSIL) }\end{array}$ & Heme/Immune \\
\hline ICD-9-CM & 795.01 & $\begin{array}{c}\text { Papanicolaou smear of cervix with atypical squamous cells of } \\
\text { undetermined significance (ASC-US) }\end{array}$ & Heme/Immune \\
\hline ICD-9-CM & 795 & Papanicolaou smear - nonspecific abnormality & Heme/Immune \\
\hline ICD-10-CM & D89.89 & $\begin{array}{l}\text { Other specified disorders involving the immune mechanism, not } \\
\text { elsewhere classified }\end{array}$ & Heme/Immune \\
\hline ICD-10-CM & D64.89 & Other specified anemias & Heme/Immune \\
\hline ICD-10-CM & D68.59 & Other primary thrombophilia & Heme/Immune \\
\hline ICD-10-CM & D61.818 & Other pancytopenia & Heme/Immune \\
\hline ICD-10-CM & D69.2 & Other nonthrombocytopenic purpura & Heme/Immune \\
\hline ICD-10-CM & D50.8 & Other iron deficiency anemias & Heme/Immune \\
\hline ICD-10-CM & D70.9 & Neutropenia, unspecified & Heme/Immune \\
\hline ICD-10-CM & D70.3 & Neutropenia due to infection & Heme/Immune \\
\hline ICD-10-CM & D50.9 & Iron deficiency anemia, unspecified & Heme/Immune \\
\hline ICD-10-CM & D50.0 & Iron deficiency anemia secondary to blood loss (chronic) & Heme/Immune \\
\hline ICD-10-CM & D84.9 & Immunodeficiency, unspecified & Heme/Immune \\
\hline ICD-10-CM & D89.42 & Idiopathic mast cell activation syndrome & Heme/Immune \\
\hline ICD-10-CM & D69.9 & Hemorrhagic condition, unspecified & Heme/Immune \\
\hline ICD-10-CM & D72.0 & Genetic anomalies of leukocytes & Heme/Immune \\
\hline ICD-10-CM & Z51.81 & Encounter for therapeutic drug level monitoring & Heme/Immune \\
\hline ICD-10-CM & Z51.5 & Encounter for palliative care & Heme/Immune \\
\hline ICD-10-CM & Z51.89 & Encounter for other specified aftercare & Heme/Immune \\
\hline ICD-10-CM & Z51.12 & Encounter for antineoplastic immunotherapy & Heme/Immune \\
\hline
\end{tabular}


Table A1. Cont.

\begin{tabular}{|c|c|c|c|}
\hline ICD & ICD-Code & Diagnosis & Categories \\
\hline ICD-10-CM & Z51.11 & Encounter for antineoplastic chemotherapy & Heme/Immune \\
\hline ICD-10-CM & D72.829 & Elevated white blood cell count, unspecified & Heme/Immune \\
\hline ICD-10-CM & D72.9 & Disorder of white blood cells, unspecified & Heme/Immune \\
\hline ICD-10-CM & D89.9 & Disorder involving the immune mechanism, unspecified & Heme/Immune \\
\hline ICD-10-CM & D75.9 & Disease of blood and blood-forming organs, unspecified & Heme/Immune \\
\hline ICD-10-CM & D72.819 & Decreased white blood cell count, unspecified & Heme/Immune \\
\hline ICD-10-CM & D68.9 & Coagulation defect, unspecified & Heme/Immune \\
\hline ICD-10-CM & D64.9 & Anemia, unspecified & Heme/Immune \\
\hline ICD-10-CM & D68.51 & Activated protein $C$ resistance & Heme/Immune \\
\hline ICD-9-CM & V65.5 & Worried well & HIV \\
\hline ICD-9-CM & V65.3 & Weight loss, intentional & HIV \\
\hline ICD-9-CM & V65.40 & Visit for counseling & HIV \\
\hline ICD-9-CM & V08 & Viruses, lymphadenopathy-associated & HIV \\
\hline ICD-9-CM & V65.49 & Surgical counseling visit & HIV \\
\hline ICD-9-CM & V65.8 & Reasons for seeking consultation & HIV \\
\hline ICD-10-CM & B20 & Human immunodeficiency virus (HIV) disease & HIV \\
\hline ICD-9-CM & V65.41 & Exercise counseling & HIV \\
\hline ICD-10-CM & Z21 & Asymptomatic human immunodeficiency virus infection status & HIV \\
\hline ICD-9-CM & 186.9 & Yolk Sac Tumour & Neoplasms \\
\hline ICD-9-CM & 193 & Wuchernde struma langhans & Neoplasms \\
\hline ICD-9-CM & 189 & WT (Wilms tumor) (HC code) & Neoplasms \\
\hline ICD-9-CM & 210.2 & Warthin's tumour & Neoplasms \\
\hline ICD-10-CM & C88.0 & Waldenstrom macroglobulinemia & Neoplasms \\
\hline ICD-9-CM & 184.4 & Vulvar malignant neoplasm (HC code) & Neoplasms \\
\hline ICD-9-CM & 182 & Uterus neoplasms & Neoplasms \\
\hline ICD-9-CM & 188.9 & Urinary bladder cancer (HC code) & Neoplasms \\
\hline ICD-10-CM & C44.90 & Unspecified malignant neoplasm of skin, unspecified & Neoplasms \\
\hline ICD-9-CM & 173.9 & Unspecified malignant neoplasm of skin, site unspecified & Neoplasms \\
\hline ICD-10-CM & C44.40 & Unspecified malignant neoplasm of skin of scalp and neck & Neoplasms \\
\hline ICD-9-CM & 173.4 & Unspecified malignant neoplasm of scalp and skin of neck & Neoplasms \\
\hline ICD-9-CM & 201.9 & $\begin{array}{l}\text { Unspecified Hodgkin's disease, site unspecified, extranodal and solid } \\
\text { organ sites }\end{array}$ & Neoplasms \\
\hline ICD-9-CM & 162.9 & Undifferentiated carcinoma of lung (HC code) & Neoplasms \\
\hline ICD-9-CM & 173.91 & Ulcers, rodent & Neoplasms \\
\hline ICD-9-CM & 174.9 & Tubular carcinoma of breast (HC code) & Neoplasms \\
\hline ICD-9-CM & 185 & Transitional cell carcinoma of prostate (HC code) & Neoplasms \\
\hline ICD-9-CM & 145.9 & The mouth cancers & Neoplasms \\
\hline ICD-9-CM & 162.3 & Syndromes, Pancoast's & Neoplasms \\
\hline ICD-9-CM & 173.99 & Sweat gland tumor, malignant & Neoplasms \\
\hline ICD-9-CM & 172.9 & Superficial spreading melanoma (HC code) & Neoplasms \\
\hline ICD-10-CM & D25.2 & Subserosal leiomyoma of uterus & Neoplasms \\
\hline ICD-9-CM & 154.1 & Stage IV carcinoma of rectum (HC code) & Neoplasms \\
\hline ICD-9-CM & 210.4 & Squamous papilloma of uvula & Neoplasms \\
\hline ICD-9-CM & 173.62 & Squamous cell skin cancer, wrist & Neoplasms \\
\hline ICD-9-CM & 173.42 & Squamous cell skin cancer, parietal & Neoplasms \\
\hline
\end{tabular}


Table A1. Cont.

\begin{tabular}{|c|c|c|c|}
\hline ICD & ICD-Code & Diagnosis & Categories \\
\hline ICD-9-CM & 173.92 & Squamous cell skin cancer & Neoplasms \\
\hline ICD-9-CM & 173.9 & Squamous Cell Epithelioma & Neoplasms \\
\hline ICD-10-CM & C44.92 & Squamous cell carcinoma of skin, unspecified & Neoplasms \\
\hline ICD-10-CM & C44.42 & Squamous cell carcinoma of skin of scalp and neck & Neoplasms \\
\hline ICD-10-CM & C44.622 & $\begin{array}{c}\text { Squamous cell carcinoma of skin of right upper limb, including } \\
\text { shoulder }\end{array}$ & Neoplasms \\
\hline ICD-10-CM & C44.329 & Squamous cell carcinoma of skin of other parts of face & Neoplasms \\
\hline ICD-10-CM & C44.321 & Squamous cell carcinoma of skin of nose & Neoplasms \\
\hline ICD-9-CM & 154.3 & Squamous cell carcinoma of anus (HC code) & Neoplasms \\
\hline ICD-9-CM & 173.41 & Skin cancer of scalp or skin of neck & Neoplasms \\
\hline ICD-9-CM & 173.31 & Skin cancer of nose & Neoplasms \\
\hline ICD-9-CM & 173.51 & Skin cancer of anterior chest & Neoplasms \\
\hline ICD-9-CM & 197 & Secondary teratoma of lung (HC code) & Neoplasms \\
\hline ICD-10-CM & C78.00 & Secondary malignant neoplasm of unspecified lung & Neoplasms \\
\hline ICD-10-CM & C78.01 & Secondary malignant neoplasm of right lung & Neoplasms \\
\hline ICD-10-CM & C78.02 & Secondary malignant neoplasm of left lung & Neoplasms \\
\hline ICD-9-CM & 154 & Recurrent squamous cell carcinoma of colorectal region (HC code) & Neoplasms \\
\hline ICD-9-CM & 173.61 & Recurrent basal cell carcinoma of shoulder & Neoplasms \\
\hline ICD-9-CM & 174.2 & $\begin{array}{l}\text { Primary malignant neoplasm of upper inner quadrant of female breast } \\
\text { (HC code) }\end{array}$ & Neoplasms \\
\hline ICD-10-CM & C44.99 & Other specified malignant neoplasm of skin, unspecified & Neoplasms \\
\hline ICD-10-CM & D26.9 & Other benign neoplasm of uterus, unspecified & Neoplasms \\
\hline ICD-10-CM & D23.9 & Other benign neoplasm of skin, unspecified & Neoplasms \\
\hline ICD-10-CM & D23.60 & $\begin{array}{l}\text { Other benign neoplasm of skin of unspecified upper limb, including } \\
\text { shoulder }\end{array}$ & Neoplasms \\
\hline ICD-10-CM & D23.30 & Other benign neoplasm of skin of unspecified part of face & Neoplasms \\
\hline ICD-10-CM & D23.70 & Other benign neoplasm of skin of unspecified lower limb, including hip & Neoplasms \\
\hline ICD-10-CM & D23.5 & Other benign neoplasm of skin of trunk & Neoplasms \\
\hline ICD-10-CM & $\mathrm{D} 23.4$ & Other benign neoplasm of skin of scalp and neck & Neoplasms \\
\hline ICD-10-CM & $\mathrm{D} 23.71$ & Other benign neoplasm of skin of right lower limb, including hip & Neoplasms \\
\hline ICD-10-CM & D23.62 & Other benign neoplasm of skin of left upper limb, including shoulder & Neoplasms \\
\hline ICD-9-CM & 210 & Neurofibroma of lip & Neoplasms \\
\hline ICD-10-CM & D49.89 & Neoplasm of unspecified behavior of other specified sites & Neoplasms \\
\hline ICD-10-CM & D49.7 & $\begin{array}{l}\text { Neoplasm of unspecified behavior of endocrine glands and other parts } \\
\text { of nervous system }\end{array}$ & Neoplasms \\
\hline ICD-10-CM & D49.0 & Neoplasm of unspecified behavior of digestive system & Neoplasms \\
\hline ICD-10-CM & D49.2 & Neoplasm of unspecified behavior of bone, soft tissue, and skin & Neoplasms \\
\hline ICD-10-CM & D48.9 & Neoplasm of uncertain behavior, unspecified & Neoplasms \\
\hline ICD-10-CM & D48.5 & Neoplasm of uncertain behavior of skin & Neoplasms \\
\hline ICD-9-CM & 172.6 & Nail bed melanoma, upper extremity (HC code) & Neoplasms \\
\hline ICD-10-CM & C90.00 & Multiple myeloma not having achieved remission & Neoplasms \\
\hline ICD-10-CM & D47.2 & Monoclonal gammopathy & Neoplasms \\
\hline ICD-9-CM & 172.5 & Melanoma, skin of trunk & Neoplasms \\
\hline ICD-9-CM & 172.7 & Melanoma, skin of lower limb & Neoplasms \\
\hline ICD-10-CM & D03.4 & Melanoma in situ of scalp and neck & Neoplasms \\
\hline ICD-10-CM & D03.59 & Melanoma in situ of other part of trunk & Neoplasms \\
\hline ICD-10-CM & D03.62 & Melanoma in situ of left upper limb, including shoulder & Neoplasms \\
\hline
\end{tabular}


Table A1. Cont.

\begin{tabular}{|c|c|c|c|}
\hline ICD & ICD-Code & Diagnosis & Categories \\
\hline ICD-10-CM & D22.9 & Melanocytic nevi, unspecified & Neoplasms \\
\hline ICD-10-CM & D22.70 & Melanocytic nevi of unspecified lower limb, including hip & Neoplasms \\
\hline ICD-10-CM & D22.60 & Melanocytic nevi of unsp upper limb, including shoulder & Neoplasms \\
\hline ICD-10-CM & D22.5 & Melanocytic nevi of trunk & Neoplasms \\
\hline ICD-10-CM & D22.4 & Melanocytic nevi of scalp and neck & Neoplasms \\
\hline ICD-10-CM & D22.61 & Melanocytic nevi of right upper limb, including shoulder & Neoplasms \\
\hline ICD-10-CM & D22.71 & Melanocytic nevi of right lower limb, including hip & Neoplasms \\
\hline ICD-10-CM & D22.39 & Melanocytic nevi of other parts of face & Neoplasms \\
\hline ICD-10-CM & D22.62 & Melanocytic nevi of left upper limb, including shoulder & Neoplasms \\
\hline ICD-10-CM & D22.72 & Melanocytic nevi of left lower limb, including hip & Neoplasms \\
\hline ICD-10-CM & C51.9 & Malignant neoplasm of vulva, unspecified & Neoplasms \\
\hline ICD-10-CM & C55 & Malignant neoplasm of uterus, part unspecified & Neoplasms \\
\hline ICD-9-CM & 174.4 & $\begin{array}{l}\text { Malignant neoplasm of upper-outer quadrant of right female breast } \\
\text { (HC code) }\end{array}$ & Neoplasms \\
\hline ICD-10-CM & C50.412 & Malignant neoplasm of upper-outer quadrant of left female breast & Neoplasms \\
\hline ICD-10-CM & C50.211 & Malignant neoplasm of upper-inner quadrant of right female breast & Neoplasms \\
\hline ICD-10-CM & C 34.12 & Malignant neoplasm of upper lobe, left bronchus or lung & Neoplasms \\
\hline ICD-10-CM & C50.919 & Malignant neoplasm of unspecified site of unspecified female breast & Neoplasms \\
\hline ICD-10-CM & C50.912 & Malignant neoplasm of unspecified site of left female breast & Neoplasms \\
\hline ICD-10-CM & C 34.90 & $\begin{array}{l}\text { Malignant neoplasm of unspecified part of unspecified bronchus or } \\
\text { lung }\end{array}$ & Neoplasms \\
\hline ICD-10-CM & C 34.92 & Malignant neoplasm of unspecified part of left bronchus or lung & Neoplasms \\
\hline ICD-10-CM & C64.9 & Malignant neoplasm of unspecified kidney, except renal pelvis & Neoplasms \\
\hline ICD-10-CM & C50.911 & Malignant neoplasm of unsp site of right female breast & Neoplasms \\
\hline ICD-10-CM & C73 & Malignant neoplasm of thyroid gland & Neoplasms \\
\hline ICD-10-CM & C64.1 & Malignant neoplasm of right kidney, except renal pelvis & Neoplasms \\
\hline ICD-10-CM & $\mathrm{C} 20$ & Malignant neoplasm of rectum & Neoplasms \\
\hline ICD-10-CM & C19 & Malignant neoplasm of rectosigmoid junction & Neoplasms \\
\hline ICD-10-CM & C61 & Malignant neoplasm of prostate & Neoplasms \\
\hline ICD-10-CM & C50.819 & Malignant neoplasm of overlapping sites of unspecified female breast & Neoplasms \\
\hline ICD-10-CM & C50.012 & Malignant neoplasm of nipple and areola, left female breast & Neoplasms \\
\hline ICD-10-CM & C06.9 & Malignant neoplasm of mouth, unspecified & Neoplasms \\
\hline ICD-10-CM & C34.31 & Malignant neoplasm of lower lobe, right bronchus or lung & Neoplasms \\
\hline ICD-10-CM & C64.2 & Malignant neoplasm of left kidney, except renal pelvis & Neoplasms \\
\hline ICD-10-CM & C54.1 & Malignant neoplasm of endometrium & Neoplasms \\
\hline ICD-10-CM & C62.11 & Malignant neoplasm of descended right testis & Neoplasms \\
\hline ICD-10-CM & C50.111 & Malignant neoplasm of central portion of right female breast & Neoplasms \\
\hline ICD-10-CM & C67.9 & Malignant neoplasm of bladder, unspecified & Neoplasms \\
\hline ICD-10-CM & C21.0 & Malignant neoplasm of anus, unspecified & Neoplasms \\
\hline ICD-10-CM & C43.9 & Malignant melanoma of skin, unspecified & Neoplasms \\
\hline ICD-10-CM & C80.1 & Malignant (primary) neoplasm, unspecified & Neoplasms \\
\hline ICD-10-CM & C62.91 & Malig neoplm of right testis, unsp descended or undescended & Neoplasms \\
\hline ICD-10-CM & C62.90 & Malig neoplasm of unsp testis, unsp descended or undescended & Neoplasms \\
\hline ICD-10-CM & D25.9 & Leiomyoma of uterus, unspecified & Neoplasms \\
\hline ICD-10-CM & D25.1 & Intramural leiomyoma of uterus & Neoplasms \\
\hline ICD-10-CM & D05.10 & Intraductal carcinoma in situ of unspecified breast & Neoplasms \\
\hline
\end{tabular}


Table A1. Cont.

\begin{tabular}{|c|c|c|c|}
\hline ICD & ICD-Code & Diagnosis & Categories \\
\hline ICD-10-CM & C81.90 & Hodgkin lymphoma, unspecified, unspecified site & Neoplasms \\
\hline ICD-10-CM & D18.00 & Hemangioma unspecified site & Neoplasms \\
\hline ICD-10-CM & D18.01 & Hemangioma of skin and subcutaneous tissue & Neoplasms \\
\hline ICD-10-CM & D47.3 & Essential (hemorrhagic) thrombocythemia & Neoplasms \\
\hline ICD-10-CM & D09.9 & Carcinoma in situ, unspecified & Neoplasms \\
\hline ICD-10-CM & D04.39 & Carcinoma in situ of skin of other parts of face & Neoplasms \\
\hline ICD-10-CM & D01.3 & Carcinoma in situ of anus and anal canal & Neoplasms \\
\hline ICD-10-CM & D36.9 & Benign neoplasm, unspecified site & Neoplasms \\
\hline ICD-10-CM & D27.9 & Benign neoplasm of unspecified ovary & Neoplasms \\
\hline ICD-10-CM & D31.30 & Benign neoplasm of unspecified choroid & Neoplasms \\
\hline ICD-10-CM & D12.3 & Benign neoplasm of transverse colon & Neoplasms \\
\hline ICD-10-CM & D24.1 & Benign neoplasm of right breast & Neoplasms \\
\hline ICD-10-CM & D36.10 & $\begin{array}{l}\text { Benign neoplasm of peripheral nerves and autonomic nervous system, } \\
\text { unspecified }\end{array}$ & Neoplasms \\
\hline ICD-10-CM & D36.13 & $\begin{array}{l}\text { Benign neoplasm of peripheral nerves and autonomic nervous system } \\
\text { of lower limb, including hip }\end{array}$ & Neoplasms \\
\hline ICD-10-CM & D11.0 & Benign neoplasm of parotid gland & Neoplasms \\
\hline ICD-10-CM & D36.7 & Benign neoplasm of other specified sites & Neoplasms \\
\hline ICD-10-CM & D10.39 & Benign neoplasm of other parts of mouth & Neoplasms \\
\hline ICD-10-CM & D32.9 & Benign neoplasm of meninges, unspecified & Neoplasms \\
\hline ICD-10-CM & D11.9 & Benign neoplasm of major salivary gland, unspecified & Neoplasms \\
\hline ICD-10-CM & D24.2 & Benign neoplasm of left breast & Neoplasms \\
\hline ICD-10-CM & D13.7 & Benign neoplasm of endocrine pancreas & Neoplasms \\
\hline ICD-10-CM & D33.3 & Benign neoplasm of cranial nerves & Neoplasms \\
\hline ICD-10-CM & D21.9 & Benign neoplasm of connective and other soft tissue, unspecified & Neoplasms \\
\hline ICD-10-CM & D21.10 & $\begin{array}{l}\text { Benign neoplasm of connective and other soft tissue of unspecified } \\
\text { upper limb, including shoulder }\end{array}$ & Neoplasms \\
\hline ICD-10-CM & D12.6 & Benign neoplasm of colon, unspecified & Neoplasms \\
\hline ICD-10-CM & D16.4 & Benign neoplasm of bones of skull and face & Neoplasms \\
\hline ICD-10-CM & D17.9 & Benign lipomatous neoplasm, unspecified & Neoplasms \\
\hline ICD-10-CM & D17.20 & $\begin{array}{l}\text { Benign lipomatous neoplasm of skin and subcutaneous tissue of } \\
\text { unspecified limb }\end{array}$ & Neoplasms \\
\hline ICD-10-CM & D17.23 & $\begin{array}{l}\text { Benign lipomatous neoplasm of skin and subcutaneous tissue of } \\
\text { right leg }\end{array}$ & Neoplasms \\
\hline ICD-10-CM & D17.21 & $\begin{array}{l}\text { Benign lipomatous neoplasm of skin and subcutaneous tissue of } \\
\text { right arm }\end{array}$ & Neoplasms \\
\hline ICD-10-CM & D17.24 & Benign lipomatous neoplasm of skin and subcutaneous tissue of left leg & Neoplasms \\
\hline ICD-10-CM & D17.22 & $\begin{array}{l}\text { Benign lipomatous neoplasm of skin and subcutaneous tissue of } \\
\text { left arm }\end{array}$ & Neoplasms \\
\hline ICD-10-CM & D17.0 & $\begin{array}{l}\text { Benign lipomatous neoplasm of skin and subcutaneous tissue of head, } \\
\text { face and neck }\end{array}$ & Neoplasms \\
\hline ICD-10-CM & C44.611 & Basal cell carcinoma skin/ unsp upper limb, inc shoulder & Neoplasms \\
\hline ICD-10-CM & C44.91 & Basal cell carcinoma of skin, unspecified & Neoplasms \\
\hline ICD-10-CM & C44.41 & Basal cell carcinoma of skin of scalp and neck & Neoplasms \\
\hline ICD-10-CM & C44.319 & Basal cell carcinoma of skin of other parts of face & Neoplasms \\
\hline ICD-10-CM & C44.519 & Basal cell carcinoma of skin of other part of trunk & Neoplasms \\
\hline ICD-10-CM & C44.311 & Basal cell carcinoma of skin of nose & Neoplasms \\
\hline
\end{tabular}


Table A1. Cont.

\begin{tabular}{lccc}
\hline ICD & ICD-Code & Diagnosis & Categories \\
\hline ICD-10-CM & Z34.81 & Encounter for suprvsn of normal pregnancy, first trimester & Pregnancy \\
\hline ICD-10-CM & Z34.80 & Encounter for supervision of other normal pregnancy, unspecified & trimester \\
\hline ICD-10-CM & Z34.83 & Encounter for supervision of other normal pregnancy, third trimester & Pregnancy \\
\hline ICD-10-CM & Z34.82 & Encounter for supervision of other normal pregnancy, second trimester & Pregnancy \\
\hline ICD-10-CM & Z34.90 & Encounter for supervision of normal pregnancy, unspecified, & Pnspecified trimester \\
\hline ICD-10-CM & Z34.93 & Encounter for supervision of normal pregnancy, unspecified, third & trimester \\
\hline ICD-10-CM & Z34.91 & Encounter for supervision of normal pregnancy, unspecified, first & Pregnancy \\
\hline ICD-10-CM & Z34.00 & Encounter for supervision of normal first pregnancy, unspecified & Pregnancy \\
\hline tCD-10-CM & Z34.03 & Encounter for supervision of normal first pregnancy, third trimester & Pregnancy \\
\hline ICD-10-CM & Z34.02 & Encounter for supervision of normal first pregnancy, second trimester & Pregnancy \\
\hline ICD-10-CM & Z34.01 & Encounter for supervision of normal first pregnancy, first trimester & Pregnancy \\
\hline ICD-10-CM & Z32.00 & Encounter for pregnancy test, result unknown & Pregnancy \\
\hline ICD-10-CM & Z32.01 & Encounter for pregnancy test, result positive & Pregnancy \\
\hline
\end{tabular}

\section{References}

1. World Health Organization. Vaccines and vaccination against yellow fever. Wkly Epidemiol. Rec. 2013, 88, 269-284.

2. Garske, T.; Van Kerkhove, M.D.; Yactayo, S.; Ronveaux, O.; Lewis, R.F.; Staples, J.E.; Perea, W.; Ferguson, N.M.; Yellow Fever Expert Committee. Yellow Fever in Africa: Estimating the burden of disease and impact of mass vaccination from outbreak and serological data. PLoS Med. 2014, 11, e1001638. [CrossRef] [PubMed]

3. Monath, T.P.; Vasconcelos, P.F.C. Yellow fever. J. Clin. Virol. 2015, 64, 160-173. [CrossRef] [PubMed]

4. North, A.F., Jr. Comments on passive immunization procedures. J. Am. Vet. Med. Assoc. 1966, 149, 688-690. [PubMed]

5. World Health Organization. New Yellow Fever Vaccination Requirements for Travellers. International Travel and Health; World Health Organization: Geneva, Switzerland, 2016.

6. Martin, M.; Weld, L.H.; Tsai, T.F.; Mootrey, G.T.; Chen, R.T.; Niu, M.; Cetron, M.S.; GeoSentinel Yellow Fever Working Group. Advanced age a risk factor for illness temporally associated with yellow fever vaccination. Emerg. Infect Dis. 2001, 7, 945-951. [CrossRef] [PubMed]

7. Mace, K.E.; Arguin, P.M. Malaria Surveillance-United States, 2014. MMWR Surveill Summ. 2017, 66, 1-24. [CrossRef] [PubMed]

8. Marasinghe, D.H.; Cheaveau, J.; Meatherall, B.; Kuhn, S.; Vaughan, S.; Zimmer, R.; Pillai, D.R. Risk of malaria associated with travel to malaria-endemic areas to visit friends and relatives: A population-based case-control study. CMAJ Open. 2020, 8, E60-E68. [CrossRef] [PubMed]

9. World Health Organization. Updates on Yellow fever vaccination recommendations for International Travellers related to current situation in Brazil. In International Travel and Health: WHO; World Health Organization: Geneva, Switzerland, 2017.

10. Potasman, I.; Pick, N.; Stringer, C.; Zuckerman, J.N. Inadequate protection against yellow fever of children visiting endemic areas. Am. J. Trop. Med. Hyg. 2001, 65, 954-957. [CrossRef] [PubMed]

11. Akselrod, H.; Swierzbinski, M.J.; Zheng, Z.; Keiser, J.; Parenti, D.M.; Simon, G.L. Characteristics and Severity of Disease among 100 Cases of Imported Malaria Seen at a U.S. University Hospital, 2000-2017. Am. J. Trop. Med. Hyg. 2018, 99, 1511-1517. [CrossRef] [PubMed]

12. Heywood, A.E.; Zwar, N. Improving access and provision of pre-travel healthcare for travellers visiting friends and relatives: A review of the evidence. J. Travel Med. 2018, 25. [CrossRef] [PubMed] 
13. Reno, E.; Quan, N.G.; Franco-Paredes, C.; Chastain, D.B.; Chauhan, L.; Rodriguez-Morales, A.J.; Henao-Martínez, A.F. Prevention of yellow fever in travellers: An update. Lancet Infect Dis. 2020, 20, e129-e137. [CrossRef]

14. Nasidi, A.; Monath, T.P.; Vandenberg, J.; Tomori, O.; Calisher, C.H.; Hurtgen, X.; Munube, G.R.; Sorungbe, A.O.; Okafor, G.C.; Wali, S. Yellow fever vaccination and pregnancy: A four-year prospective study. Trans. R. Soc. Trop. Med. Hyg. 1993, 87, 337-339. [CrossRef]

15. Tattevin, P.; Depatureaux, A.G.; Chapplain, J.M.; Dupont, M.; Souala, F.; Arvieux, C.; Poveda, J.D.; Michelet, C. Yellow fever vaccine is safe and effective in HIV-infected patients. AIDS 2004, 18, 825-827. [CrossRef] [PubMed]

16. Sicre de Fontbrune, F.; Arnaud, C.; Cheminant, M.; Boulay, A.; Konopacki, J.; Lapusan, S.; Robin, C.; Bernaudin, F.; Suarez, F.; Simon, F.; et al. Immunogenicity and Safety of Yellow Fever Vaccine in Allogeneic Hematopoietic Stem Cell Transplant Recipients After Withdrawal of Immunosuppressive Therapy. J. Infect. Dis. 2017, 217, 494-497. [CrossRef]

17. de Jong, W.; de Man, R.A.; Dalm, V.A.S.H.; Reusken, C.B.E.M.; Goeijenbier, M.; van Gorp, E.C.M. Yellow fever vaccination for immunocompromised travellers: Unjustified vaccination hesitancy? J. Travel Med. 2019, 26, taz015. [CrossRef] [PubMed]

18. Shearer, F.M.; Moyes, C.L.; Pigott, D.M.; Brady, O.J.; Marinho, F.; Deshpande, A.; Longbottom, J.; Browne, A.J.; Kraemer, M.U.G.; O'Reilly, K.M.; et al. Global yellow fever vaccination coverage from 1970 to 2016: An adjusted retrospective analysis. Lancet Infect Dis. 2017, 17, 1209-1217. [CrossRef]

19. Hamer, D.H.; Angelo, K.; Caumes, E.; van Genderen, P.J.J.; Florescu, S.A.; Popescu, C.P.; Perret, C.; McBride, A.; Checkley, A.; Ryan, J.; et al. Fatal Yellow Fever in Travelers to Brazil, 2018. MMWR Morb Mortal Wkly Rep. 2018, 67, 340-341. [CrossRef] [PubMed]

20. Flasche, S.; Jit, M.; Rodríguez-Barraquer, I.; Coudeville, L.; Recker, M.; Koelle, K.; Milne, G.; Hladish, T.J.; Perkins, T.A.; Cummings, D.A.T.; et al. The Long-Term Safety, Public Health Impact, and Cost-Effectiveness of Routine Vaccination with a Recombinant, Live-Attenuated Dengue Vaccine (Dengvaxia): A Model Comparison Study. PLoS Med. 2016, 13, e1002181. [CrossRef] [PubMed]

21. Goldie, S. A public health approach to cervical cancer control: Considerations of screening and vaccination strategies. Int. J. Gynecol. Obstet. 2006, 94, S95-S105. [CrossRef]

(C) 2020 by the authors. Licensee MDPI, Basel, Switzerland. This article is an open access article distributed under the terms and conditions of the Creative Commons Attribution (CC BY) license (http://creativecommons.org/licenses/by/4.0/). 